Annuaire suisse de politique de développement

9 | 1990

Annuaire Suisse - Tiers Monde 1990

\title{
Engagement du personnel de la coopération technique suisse
}

Der Personaleinsatz in der schweizerischen Entwicklungszusammenarbeit

Rudolf Dannecker

\section{(2) OpenEdition}

1 Journals

Édition électronique

URL : http://journals.openedition.org/aspd/1328

DOI : $10.4000 /$ aspd. 1328

ISSN : 1663-9669

Éditeur

Institut de hautes études internationales et du développement

Édition imprimée

Date de publication : 1 janvier 1990

Pagination : 247-263

ISSN : 1660-5934

Référence électronique

Rudolf Dannecker, «Engagement du personnel de la coopération technique suisse », Annuaire suisse

de politique de développement [En ligne], 9 | 1990, mis en ligne le 31 mars 2013, consulté le 08

septembre 2020. URL : http://journals.openedition.org/aspd/1328 ; DOI : https://doi.org/10.4000/

aspd. 1328

Ce document a été généré automatiquement le 8 septembre 2020

(C) The Graduate Institute I Geneva 


\title{
Engagement du personnel de la coopération technique suisse
}

Der Personaleinsatz in der schweizerischen Entwicklungszusammenarbeit

\author{
Rudolf Dannecker
}

\section{NOTE DE L'ÉDITEUR}

En français, résumé seulement. Lire l'article original en allemand dans Schweizerisches Jahrbuch für Entwicklungspolitik : « Der Personaleinsatz in der schweizerischen Entwicklungszusammenarbeit », http://sjep.revues.org/1157.

\section{RÉSUMÉS}

Dans la coopération au développement le succès peut parfois largement dépendre du personnel expatrié engagé dans un projet ou un programme et de sa capacité à coopérer avec ses partenaires locaux dans un contexte institutionnel et culturel qu'il ne connaît pas toujours très bien. Cet article présente les fonctions d'un coopérant ainsi que le profil du personnel que la coopération suisse cherche à recruter ainsi que leur évolution en fonction des changements qui interviennent dans la coopération au développement. Toute la séquence des questions liées au personnel de coopération technique est abordée : les motivations du coopérant, les critères et les modalités de recrutement, les rôles complexes du coopérant au carrefour des attentes d'institutions diverses, le retour et la réintégration dans son pays d'origine. L'article se termine par des réflexions sur les perspectives de la coopération technique. 


\section{AUTEUR}

\section{RUDOLF DANNECKER}

Vice-directeur ; Direction de la Coopération au développement et de l'aide humanitaire, Berne 